Article

\title{
Studies on Pitting Corrosion of Al-Cu-Li Alloys Part I: Effect of Li Addition by Microstructural, Electrochemical, In-situ, and Pit Depth Analysis
}

\author{
Xiaowei Lei ${ }^{1,2}{ }^{(D)}$, Alireza Saatchi ${ }^{2}$, Elmira Ghanbari ${ }^{2}$, Runze Dang ${ }^{1}$, Wenzhe Li $^{1}$, Nan Wang ${ }^{1, *}$ \\ and Digby D. Macdonald ${ }^{2}$ * \\ 1 MOE Key Laboratory of Materials Physics and Chemistry under Extraordinary Conditions, \\ School of Natural and Applied Sciences, Northwestern Polytechnical University, Xi'an 710072, China; \\ xiaowei_lei@nwpu.edu.cn (X.L.); dangrunze@mail.nwpu.edu.cn (R.D.); 1wz913157048@163.com (W.L.) \\ 2 Department of Materials Science and Engineering, University of California at Berkeley, Berkeley, CA 94720, \\ USA; alireza.saatchi@berkeley.edu (A.S.); elmira.ghanbari@berkeley.edu (E.G.) \\ * Correspondence: nan.wang@nwpu.edu.cn (N.W.); macdonald@berkeley.edu (D.D.M.)
}

Received: 19 April 2019; Accepted: 14 May 2019; Published: 16 May 2019

check for updates

\begin{abstract}
To analyze the effect of lithium and microstructure on the pitting corrosion behavior of aluminum alloys, three types of aluminum alloys were studied via scanning electron microscopy, transmission electron microscopy, electrochemical polarization, and by immersion tests coupled with in-situ observation of pitting and statistical analysis of pit depths measured by surface profilometry. It was found that, with increasing lithium content, the resistance to pitting corrosion was enhanced and the passive range was enlarged. In-situ observation revealed that the development of pitting corrosion exhibited three stages, including an initial slow nucleation stage (Stage I), a fast development stage (Stage II), and a stabilized growth stage (Stage III). Higher lithium content contributed to shorter time periods of Stages I and II, resulting in faster pitting evolution and a higher number of pits. However, the pits were generally shallower for the specimen with the highest lithium content, which is in agreement with the results of the electrochemical analysis.
\end{abstract}

Keywords: Al-Cu-Li alloys; microstructure; pitting corrosion; polarization; TEM

\section{Introduction}

The primary driving force for research and development on aviation aluminum alloys is to reduce the weight of aircraft [1-4]. Owing to the low density, high strength, and excellent fatigue crack resistance, $\mathrm{Al}-\mathrm{Cu}-\mathrm{Li}$ alloys have received increasing attention during the last two decades [5-10]. Being the lightest metallic element in the nature, lithium contributes to $6 \%$ increase in elastic modulus and $3 \%$ decrease in weight for aluminum alloys by adding $1 \mathrm{wt} . \%$ of lithium [2,3]. However, as lithium is an active alkali metal, adding lithium may have a significant influence on the corrosion performance of aluminum alloys [5,11,12], though the chemical properties of an alloying element should be very different from those at its elementary substance state [13].

Microstructure is a crucial factor that influences the corrosion performance of aluminum alloys [14]. Particularly, the amount, size, location, and chemistry of precipitated phases show significant effects on the pitting corrosion behavior of aluminum alloys [8,15-18]. Abundant studies have shown that the addition of $\mathrm{Li}$ can change the microstructures of $\mathrm{Al}$ alloys dramatically [2,3,7,19-22], especially for the precipitated phases induced by $\mathrm{Li}$ addition. For instance, the addition of lithium to $0.5 \mathrm{wt}$.\% facilitates the precipitation of $\theta^{\prime}\left(\mathrm{Al}_{2} \mathrm{Cu}\right)$ phase with a refined dispersion in the matrix of $2 x x x$ series aluminum alloys, while higher lithium content $(1.0 \mathrm{wt} . \%)$ results in the formation of $\mathrm{T}_{1}\left(\mathrm{Al}_{2} \mathrm{CuLi}\right)$ as the dominant precipitant [23]. $\mathrm{T}_{2}\left(\mathrm{Al}_{6} \mathrm{CuLi}_{3}\right)[16]$ and $\delta^{\prime}\left(\mathrm{Al}_{3} \mathrm{Li}\right)$ [24,25] phases are also common precipitates in 
Al-Cu-Li alloys. According to Li et al. $[16,26,27]$, the $\theta^{\prime}$ phase usually acts as the cathode compared to the matrix, while $T_{1}$ and $T_{2}$ are anodic to the alloy base, indicating that further addition of lithium can change the initiation behavior of pitting corrosion. However, the evolution of pitting corrosion on aluminum alloys in response to lithium content has not been systematically studied. Moreover, Carrick et al. [11] reported that the susceptibility of intergranular corrosion and pitting corrosion is higher for lithium-containing AA2099 alloy compared with AA2024, which has no lithium, whereas, based on work of Kumai et al. [24], the addition of lithium does not show deteriorative effects on the pitting resistance of $\mathrm{Al}$ alloys. The controversy inspires us to carry out careful analyses to clarify the effect of lithium addition on the corrosion sensitivity of $\mathrm{Al}$ alloys.

In this paper, which is the first part of a broader study on the subject, the microstructures of 2029, 2060, and 2098 aluminum alloys, having lithium content ranging from 0 to $1.29 \mathrm{wt}$. , were characterized. The corrosion behavior of the three alloys were investigated. The mechanisms for the pitting evolution and formation of severe localized corrosion are discussed. This work will be followed by further analysis using the point defect model in the second part of this series.

\section{Experimental}

\subsection{Materials and Microstructure Characterization}

The chemical compositions of the aluminum alloys used in this study, which are AA2029-T8 (\#S1), AA2060-T8 (\#S2), and AA2098-T851 (\#S3), are listed in Table 1. For the three aluminum alloys from $\mathrm{S} 1$ to $\mathrm{S} 3$, the compositional difference is mainly the increasing content of lithium, as the content is shown by weight fraction. Magnesium, manganese, and zinc contents are also slightly different. The microstructures of the $\mathrm{Al}$ alloys were characterized using an Olympus optical microscope (Tokyo, Japan) and a TESCAN Vega3 scanning electron microscope (SEM) (Brno, Czech Republic). The microstructures were revealed with an etching solution of $\mathrm{NaF}(0.5 \mathrm{~g}), \mathrm{HNO}_{3}(1 \mathrm{~mL}), \mathrm{HCl}(2 \mathrm{~mL})$, and $\mathrm{H}_{2} \mathrm{O}(97 \mathrm{~mL})$. Transmission electron microscopy (TEM) specimens were twin-jet polished in the electrolyte with $25 \% \mathrm{HNO}_{3}$ and $75 \%$ methyl alcohol at $-40{ }^{\circ} \mathrm{C}$. TEM characterizations were performed on a FEI Talos F200X microscope (Hillsboro, OR, USA) with an acceleration voltage of $200 \mathrm{kV}$.

Table 1. Chemical compositions of the three aluminum alloys (wt.\%).

\begin{tabular}{cccccccccc}
\hline Number & Material & $\mathbf{C u}$ & $\mathbf{L i}$ & $\mathbf{M g}$ & $\mathbf{M n}$ & $\mathbf{A g}$ & $\mathbf{Z r}$ & $\mathbf{Z n}$ & Al \\
\hline S1 & $2029-\mathrm{T} 8$ & 3.46 & - & 0.80 & 0.26 & 0.04 & - & 0.01 & Bal. \\
S2 & $2060-\mathrm{T} 8$ & 3.63 & 0.78 & 0.67 & 0.25 & 0.04 & 0.06 & 0.29 & Bal. \\
S3 & $2098-\mathrm{T} 851$ & 3.71 & 1.29 & 0.26 & 0.03 & 0.03 & 0.06 & 0.01 & Bal. \\
\hline
\end{tabular}

\subsection{In-Situ Immersion Test}

For the in-situ immersion tests, the experimental set-up is depicted in Figure 1. The specimen was attached to the bottom of a small tank. The specimens were ground to 1200 grit, polished with $1 \mu \mathrm{m}$ diamond suspension, rinsed with deionized water, degreased in ethanol, and dried with a stream of $\mathrm{N}_{2}$ gas. In order to avoid contamination of the objective lens by the solution, a lens with a low magnification $(10 \times)$ is applied, and the total magnification of the observation system is $50 \times$. Once the solution is poured to the tank, the software records the surface morphology every $1 \mathrm{~min}$. Since pitting corrosion occurs very quickly in $\mathrm{Cl}^{-}$-containing solution, we used $0.001 \mathrm{M} \mathrm{NaCl}$ solution for the in-situ immersion test, allowing us to effectively record the accumulated numbers of corrosion pits. A higher concentration of $\mathrm{Cl}^{-}$solution $(0.6 \mathrm{M} \mathrm{NaCl})$ was chosen for the observation of pitting morphologies, and the 3D morphologies of the pits were characterized by using a Zygo 3D optical surface profilometer (Berwyn, PA, USA). 


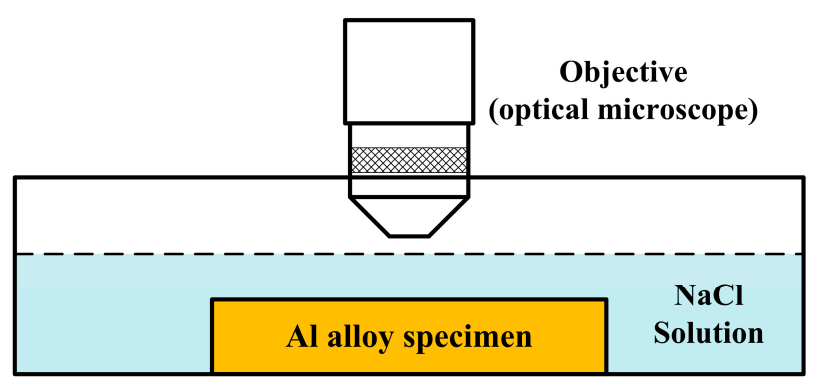

Figure 1. Schematic for in-situ observation of the immersion test.

\subsection{Electrochemical Measurements}

The working electrodes (WEs) with dimensions of $10 \times 10 \times \mathrm{T} \mathrm{mm}^{3}$ were cut from the received specimens, where $\mathrm{T}$ is the thickness of the as-received material. The rolling direction is in the $10 \times 10 \mathrm{~mm}^{2}$ surface, and T is along the short transverse direction. Prior to all experiments, the WEs were ground with $\mathrm{SiC}$ papers to 1200 grit, rinsed with deionized water, degreased in ethanol, and dried. The solution for the electrochemical measurements was borate buffer, prepared by $0.0225 \mathrm{M} \mathrm{H}_{3} \mathrm{BO}_{3}$ and $0.11 \mathrm{M} \mathrm{Na}_{2} \mathrm{~B}_{4} \mathrm{O}_{7} \cdot 10 \mathrm{H}_{2} \mathrm{O}$, with $0.01 \mathrm{M} \mathrm{NaCl}(\mathrm{pH}=8.4)$. We used the borate buffer solution for the electrochemical tests in order to keep the $\mathrm{pH}$ constant. The solution was deaerated with $\mathrm{N}_{2}$ gas, and the measurements were conducted at ambient temperature $\left(20^{\circ} \mathrm{C}\right)$. A Solartron Analytical Modulab (Farnborough, Hampshire, UK) was employed to conduct the polarization measurements. A platinum mesh and a saturated calomel electrode (SCE) were used as the counter electrode and the reference electrode, respectively. A Luggin capillary, which was filled with the same electrolyte as the test solution, was used as a salt bridge. Prior to the electrochemical measurements, the WE was cathodically polarized at $-0.5 \mathrm{~V}$ (vs. OCP) for $5 \mathrm{~min}$ to produce a reproducible surface. Subsequently, the WE was stabilized at the OCP for $900 \mathrm{~s}$. After that, the potentiodynamic polarization curves were recorded with a scanning rate of $0.33 \mathrm{mV} / \mathrm{s}$. Potentiostatic polarization tests were performed by applying $-0.45 \mathrm{~V}_{\mathrm{SCE}}$ to the WEs for $12 \mathrm{~h}$.

\section{Results}

\subsection{Microstructures}

Figure 2 shows the microstructures of the three types of aluminum alloys. Specimen S1 exhibits equiaxed grain feature with an average grain size of 60-100 $\mu \mathrm{m}$. In comparison, larger grains decorated with small and irregularly shaped grains can be seen in S2. The microstructure of S3 is distributed along one direction, which should be the rolling direction, as the alloy was stress-relieved by stretching (T851 treatment). Also, it can be seen that $\mathrm{S} 3$ shows distinctly different grain morphologies, and very large grains are presented. Many large intermetallic phases are found in the SEM images of the three alloys, energy dispersive spectrum (EDS) characterizations were performed, as shown in Figure 3 and Table 2.
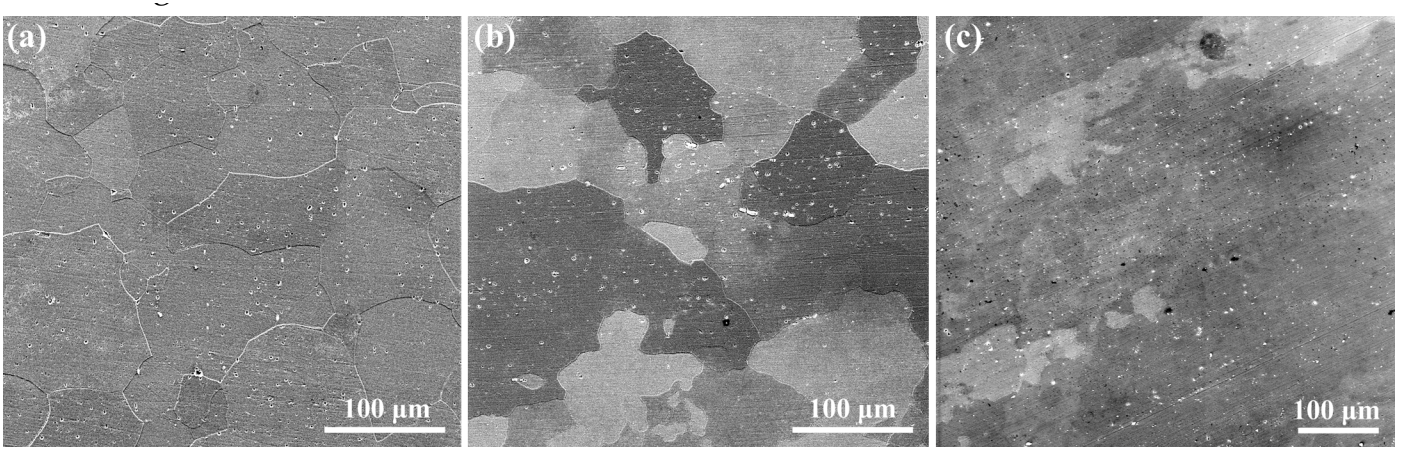

Figure 2. SEM microstructures of the aluminum alloys. (a) S1, (b) S2 and (c) S3. 

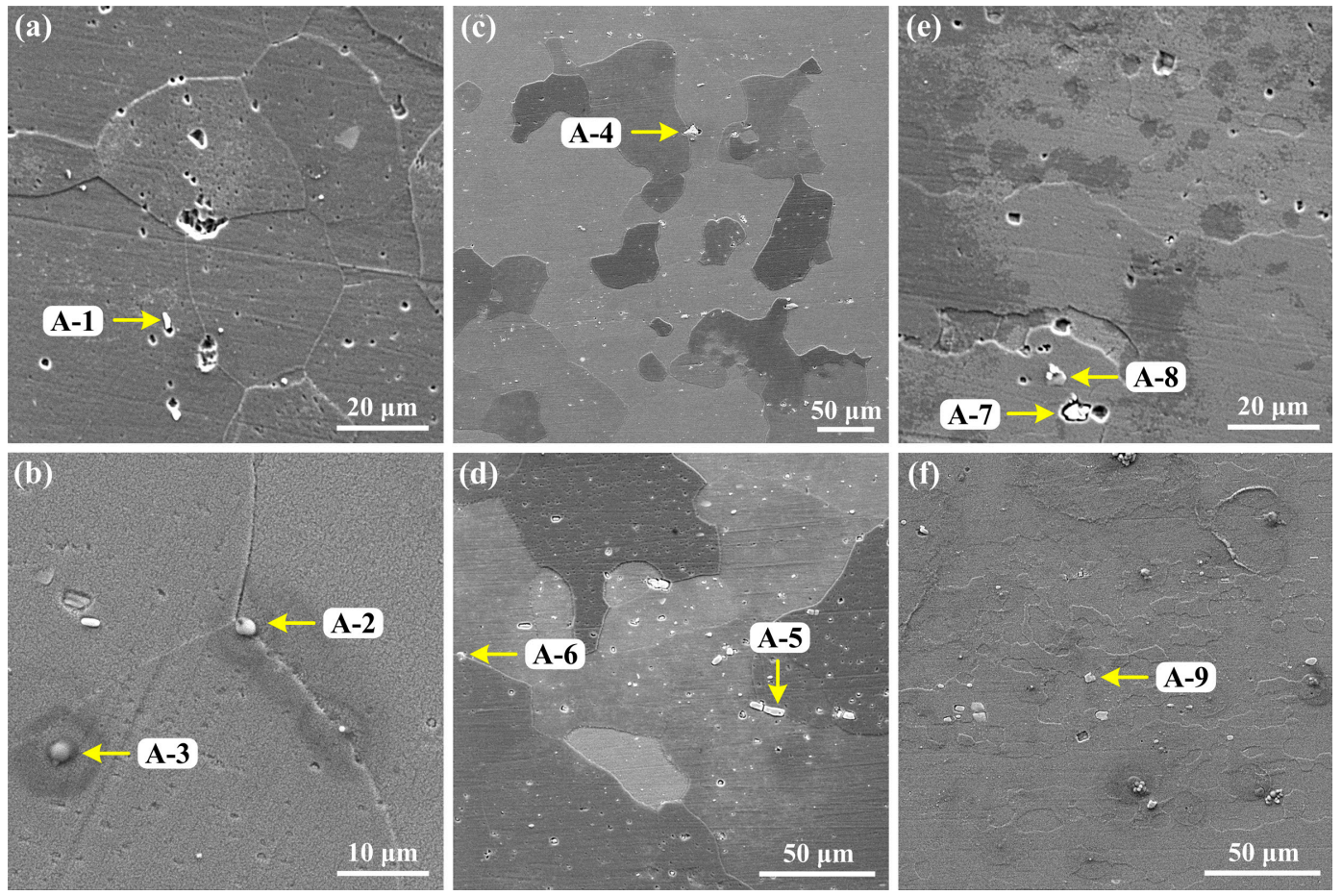

Figure 3. SEM/EDS characterization of intermetallic phases in the aluminum alloys. (a) and (b): S1, (c) and (d): S2, (e) and (f): S3. A-1 to A-9 are the SEM/EDS characterization points.

Table 2. SEM/EDS analyzing results of points A-1 to A-9, as marked in Figure 3. (wt.\%).

\begin{tabular}{cccccc}
\hline \multicolumn{2}{c}{ Element } & Al & $\mathbf{C u}$ & $\mathbf{O}$ & $\mathbf{A l} / \mathbf{C u}$ \\
\hline \multirow{4}{*}{ S1 } & A-1 & 13.01 & 69.94 & 17.05 & 0.186 \\
& A-2 & 43.75 & 13.28 & 42.97 & 3.294 \\
& A-3 & 35.68 & 12.09 & 52.23 & 2.951 \\
\hline \multirow{4}{*}{ S2 } & A-4 & 18.85 & 72.84 & 8.31 & 0.259 \\
& A-5 & 15.59 & 69.43 & 14.98 & 0.225 \\
& A-6 & 49.30 & 42.66 & 8.04 & 1.156 \\
\hline \multirow{4}{*}{ S3 } & A-7 & 2.13 & 87.92 & 9.95 & 0.024 \\
& A-8 & 56.74 & 17.06 & 26.20 & 3.326 \\
& A-9 & 19.74 & 71.51 & 8.75 & 0.276 \\
\hline
\end{tabular}

For specimen S1, the large intermetallic particles are mainly located at the grain boundaries, this characteristic is demonstrated by the large pits, caused by etching, at the grain boundaries in Figure 3a. In Figure 3c,d, specimen S2 also shows large intermetallic phases at the grain boundaries, but the size and distribution of particles in specimen S3 seem to be even within and in between the grains. As for the chemical composition, all the intermetallic phases marked by the yellow arrows in Figure 3 primarily contain $\mathrm{Al}, \mathrm{Cu}$, and $\mathrm{O}$. However, by comparing the shape of the intermetallic phases, the $\mathrm{Cu}$ content, and the ratio of $\mathrm{Al}: \mathrm{Cu}(\mathrm{Al} / \mathrm{Cu})$, we found that the spherical and quasi-spherical particles possess lower $\mathrm{Cu}$ content $(\mathrm{Al} / \mathrm{Cu}$ is around 3$)$, while those with the narrow strip and irregular shapes contains very high $\mathrm{Cu}$ content. The relationship between the shape and composition of the intermetallic phase is out of the scope of the present paper and will not be discussed further.

The characteristics of the small intermetallic phases were analyzed by TEM, as shown in Figure 4 . Scanning transmission electron microscopy (STEM) mode was used to carry out EDS characterizations. A large number of intermetallic phases are found in the three alloys by TEM characterization, but the microstructure of specimen S3 is distinctly different from that of S1 and S2. The needle-shaped precipitates in $\mathrm{S} 3$ are a typical feature of the $\mathrm{T}_{1}$ phase $\left(\mathrm{Al}_{2} \mathrm{CuLi}\right)[3,28]$, whereas larger phases like the 
size of "P-6" in Figure $4 \mathrm{f}$ are rarely seen in S3 by TEM. The chemical compositions of the intermetallic phases marked P-1 to P-6 are listed in Table 3. The intermetallic phases P-1 to P-3 of specimen S1 show the highest $\mathrm{Mg}$ content (around $1 \mathrm{wt}$ \%) and are regarded as being the $\mathrm{S}$ phase $\left(\mathrm{Al}_{2} \mathrm{CuMg}\right)[29]$. In comparison, the P-4 and P-5 phases in S2 have higher Mn content than the other two alloys, and the Mn content of P-4 is up to 11.96 wt.\%, which could correspond to $\mathrm{Al}_{20} \mathrm{Cu}_{2} \mathrm{Mn}_{3}$ [30]. The P-6 phase in specimen $\mathrm{S} 3$ mainly possesses $\mathrm{Al}$ and $\mathrm{Cu}$ and no $\mathrm{Mg}$, and little $\mathrm{Mn}$ was detected. It should be noted that, according to Table 1, specimens S2 and S3 contain Li, but it was not detected due to the limitation of the TEM used for the present characterization. Hence, P-6 could be an Al-Cu or Al-Cu-Li intermetallic phase.
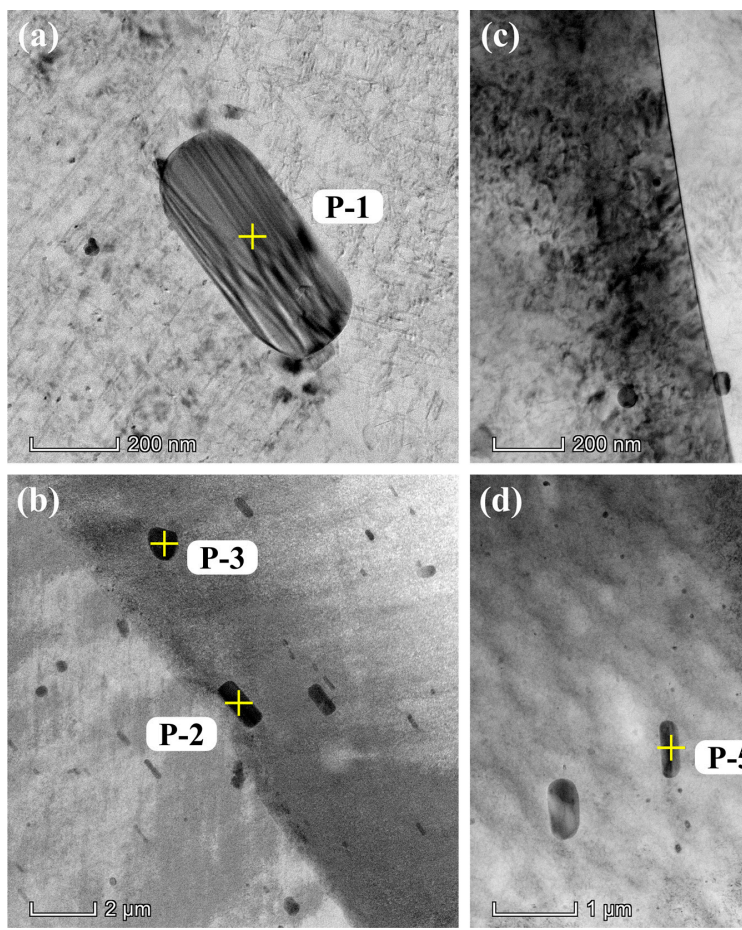
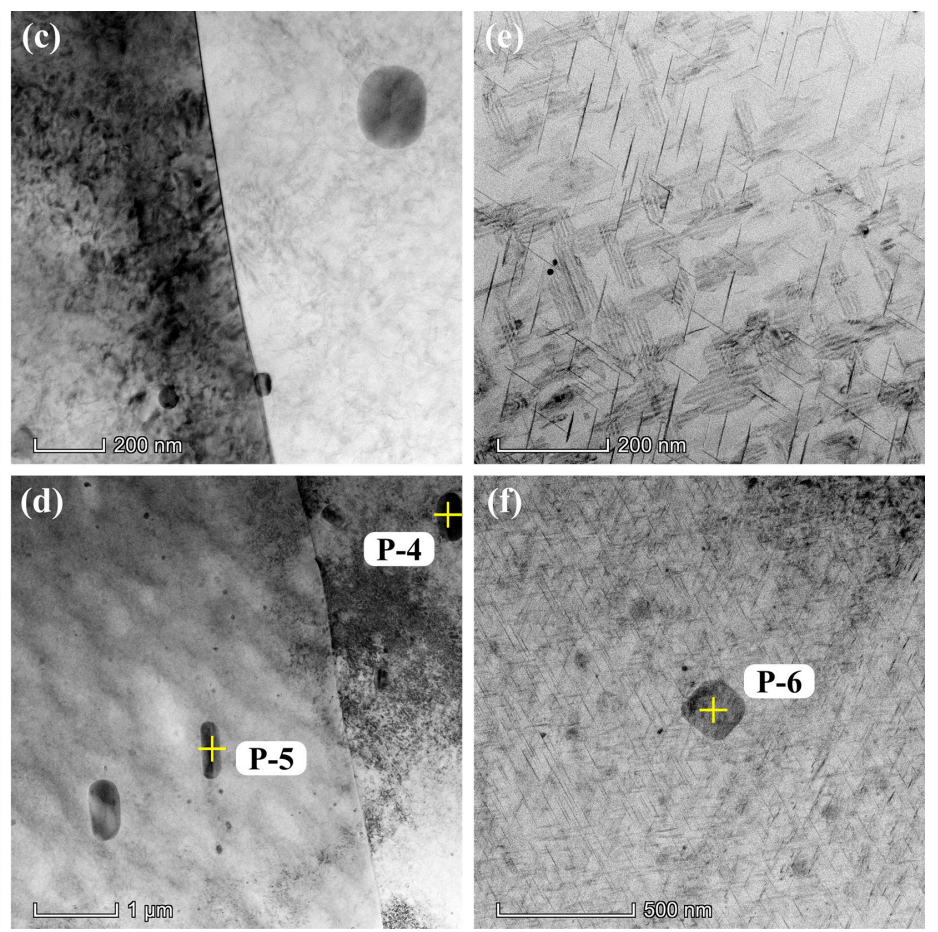

Figure 4. TEM images of the aluminum alloys. (a) and (b): S1, (c) and (d): S2, (e) and (f): S3. P-1 to P-6 are the STEM/EDS characterization points.

Table 3. STEM/EDS analyzing results of points P-1 to P-6, as marked in Figure 4. (wt.\%).

\begin{tabular}{cccccccc}
\hline \multicolumn{2}{c}{ Element } & A1 & Cu & O & Mg & Mn & C \\
\hline \multirow{4}{*}{ S1 } & P-1 & 90.76 & 6.03 & 1.99 & 1.22 & - & - \\
& P-2 & 92.67 & 5.00 & 0.19 & 1.18 & 0.96 & - \\
& P-3 & 85.39 & 7.59 & 0.21 & 0.99 & 5.82 & - \\
\hline \multirow{2}{*}{ S2 } & P-4 & 75.72 & 10.98 & - & - & 11.96 & 1.34 \\
& P-5 & 74.26 & 9.55 & - & 0.68 & 9.77 & 5.74 \\
\hline \multirow{2}{*}{ S3 } & P-6 & 87.21 & 11.20 & 0.83 & - & 0.76 & - \\
\hline
\end{tabular}

\subsection{Electrochemical Measurements}

The corrosion performance of the aluminum alloys was analyzed by potentiodynamic polarization measurement in borate buffer solution with $0.01 \mathrm{M} \mathrm{NaCl}$, and the results are shown in Figure 5 . It should be noted that the potentiodynamic test for each specimen was repeated nine times, and the results shown here are the ones that are closest to the average values of corrosion potential $\left(E_{\mathrm{corr}}\right)$, pitting potential $\left(E_{\mathrm{p}}\right)$, and passive current density $\left(i_{\mathrm{p}}\right)$. In Figure 5 , the order of $E_{\mathrm{p}}$ is $\mathrm{S} 1<\mathrm{S} 2<\mathrm{S} 3$, indicating that sequence of pitting resistance is $\mathrm{S} 1<\mathrm{S} 2<\mathrm{S} 3$. However, the passive currents are similar for all three aluminum alloys. The average values of $E_{\mathrm{p}}$ and $E_{\mathrm{corr}}$ of the three alloys are depicted 
in Figure 6. The $E_{\text {pit }}$ values of S1, S2 and S3 are $-441 \pm 70 \mathrm{mV},-321 \pm 75 \mathrm{mV}$, and $-152 \pm 76 \mathrm{mV}$, respectively, and the $E_{\text {corr }}$ values of $\mathrm{S} 1$, S2 and S3 are $-548+74 \mathrm{mV},-523+78 \mathrm{mV}$, and $-576+70 \mathrm{mV}$, respectively. The gaps between $E_{\text {pit }}$ and $E_{\text {corr }}$ are regarded as being the passive range, as marked by the yellow bars. S3 shows the noblest pitting potential and lowest corrosion potential, and, thereby, possesses the widest passive range $(424 \mathrm{mV})$. In comparison, $\mathrm{S} 2$ has a slightly larger passive range than S1, indicating the medium pitting resistance of S2. It seems that, for the present lithium content range and corrosion environment, the aluminum alloy with higher lithium content exhibits the better pitting resistance.

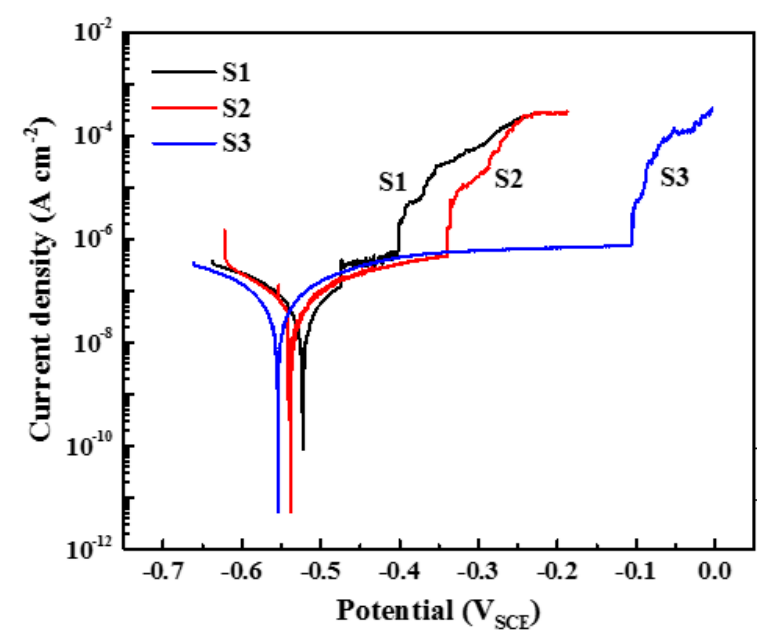

Figure 5. Potentiodynamic polarization curves of aluminum alloys in borate buffer solution with $0.01 \mathrm{M} \mathrm{NaCl}$.

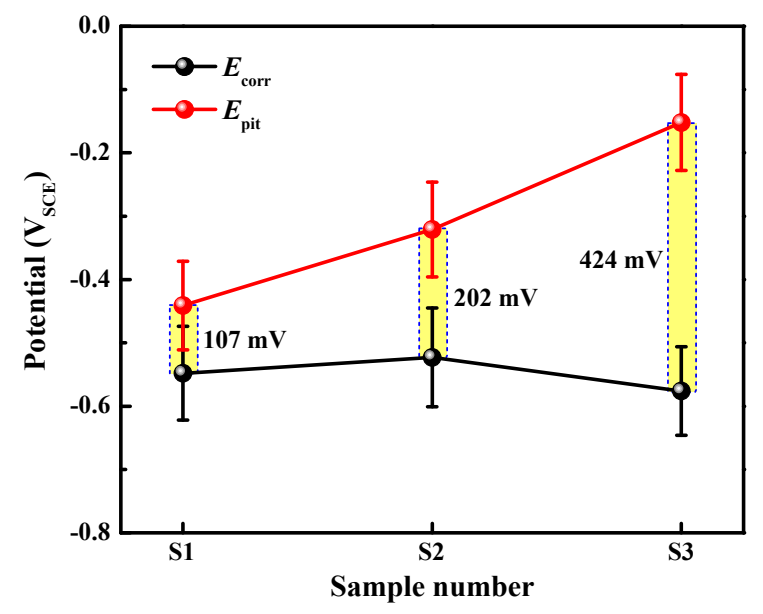

Figure 6. Comparison of the corrosion potentials and pitting potentials of the three types of aluminum alloys. The data was obtained based upon 9 parallel experiments for each specimen.

The electrochemical corrosion behavior of the aluminum alloys was also analyzed via potentiostatic polarization measurement, and the results are shown in Figure 7 . The applied potential $\left(-0.45 \mathrm{~V}_{\mathrm{SCE}}\right)$ is within the passive region of the alloys. In the beginning period, many current spikes can be found for specimens S1 and S2, which means that the passive films on S1 and S2 are subjected to large numbers of meta-stable breakdown and repassivation events. In comparison, no spike is found on specimen S3, suggesting that the passive film on S3 is more stable. After about $1 \times 10^{4} \mathrm{~s}$, the current densities of specimens S1 and S3 reached plateaus, whereas the current density of S2 progressively increases. Finally, the sequence of stable current density $(12 \mathrm{~h})$ lies in the order of $i_{\mathrm{S} 1} \approx i_{\mathrm{S} 2}>i_{\mathrm{S} 3}$. Taking the potentiodynamic results into consideration, it is seen that the addition of lithium could enhance 
the electrochemical corrosion resistance of the alloys under the current corrosion condition. A low percentage of lithium (0.78 wt.\%) shows a moderately positive effect on the resistance to general corrosion, while the addition of $1.29 \mathrm{wt} . \%$ lithium improves the pitting resistance significantly.

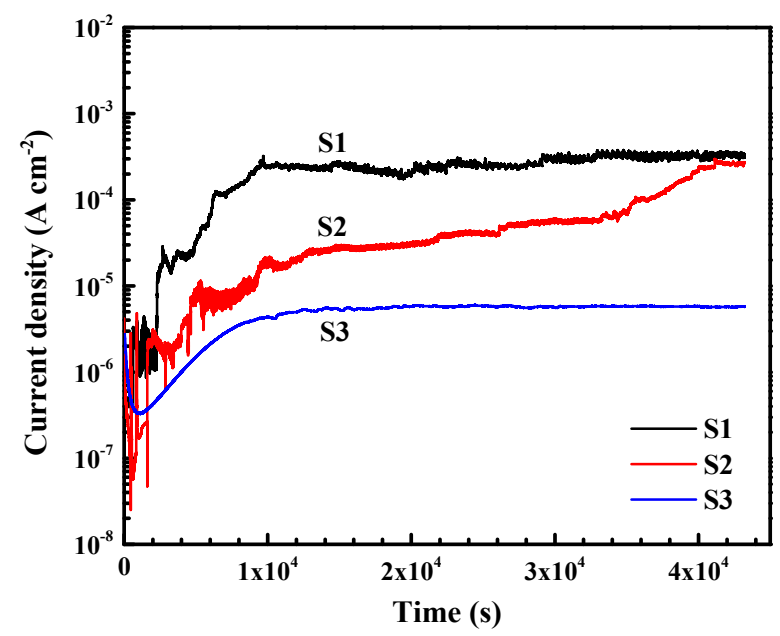

Figure 7. Potentiostatic polarization curves of aluminum alloys in borate buffer solution with $0.01 \mathrm{M}$ $\mathrm{NaCl}$. The applied potential is $-0.45 \mathrm{~V}_{\mathrm{SCE}}$.

\subsection{Immersion Test}

\subsubsection{Number of Pits}

An immersion test is a cogent method for investigating the corrosion performance of metals and alloys. In this study, an in-situ approach is used to observe the development of corrosion on the specimen surfaces. By utilizing the experimental set up depicted in Figure 1, pitting morphologies were obtained, as shown in Figure 8. As pitting corrosion occurs very quickly at higher concentrations of $\mathrm{NaCl}$ solution (such as $0.6 \mathrm{M} \mathrm{NaCl}$ solution in which pitting occurs within $1 \mathrm{~min}$ ), we used $0.001 \mathrm{M}$ $\mathrm{NaCl}$ solution for the in-situ observation of pitting evolution. Note that the solution used here is without the borate buffer, such that the stable pitting can occur under OCP conditions. In Figure 8, pits can be clearly seen on the three alloys after $5 \mathrm{~min}$ of immersion, and more pits are found on the surface of specimen S3 at $5 \mathrm{~min}$ than on S1 and S2. With increasing immersion time, more pits appeared on the specimens, and the existing small pits grew to larger ones. Meanwhile, S1 and S2 seem to have larger pits than S3.

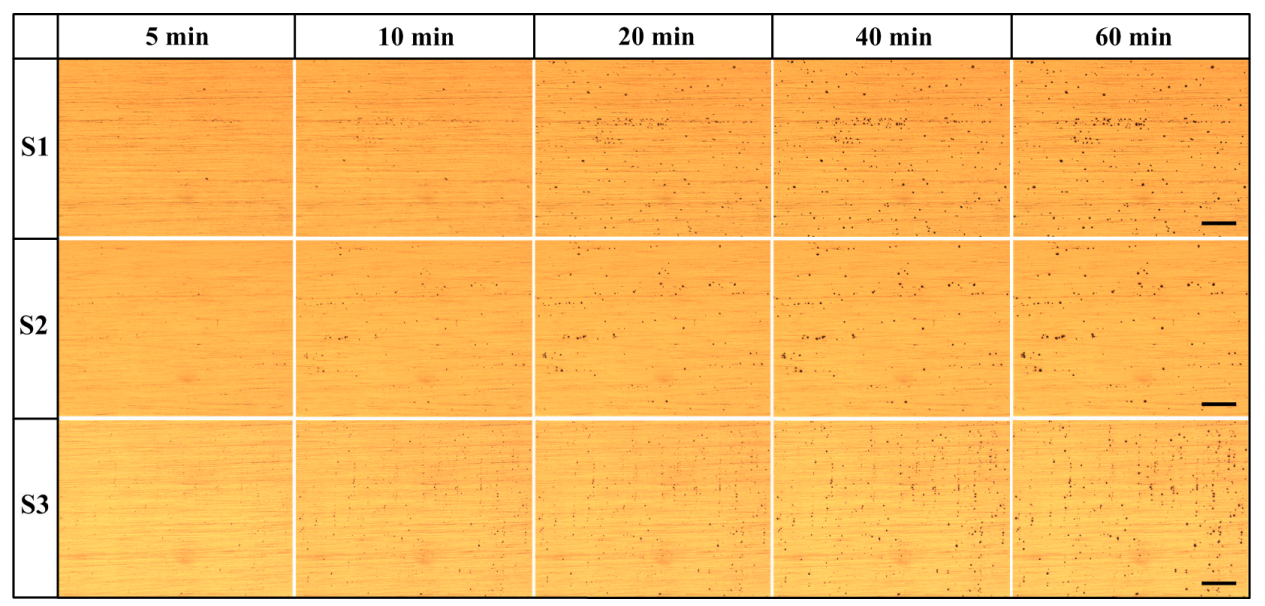

Figure 8. Evolution of pits on aluminum alloys in aerated $0.001 \mathrm{M} \mathrm{NaCl}$ solution. Scale bar is $150 \mu \mathrm{m}$. 
Figure 9 presents the cumulative numbers of pits $\left(N_{t}\right)$ as a function of immersion time. According to the shape of the curves, the development of pitting events can be divided into three stages: (I) Initial, slow nucleation stage: Pitting begins to occur, but the increasing rate of $N_{t}$ is at a low level; (II) Fast development stage: $N_{t}$ rises dramatically within a short period; (III) Stabilized growth stage: $N_{\mathrm{t}}$ increases slowly and finally reach a plateau. The three stages reasonably describe the development of corrosion at the surfaces of aluminum alloys. Pitting corrosion usually occurs at sensitive sites, such as at inclusions, precipitates, grain boundaries, etc. [14]. If these sites are consumed, pitting corrosion is restricted to new positions on the surface. Therefore, the number of pits will gradually reach a plateau (Stage III), although the pre-existing pits may keep growing. In Figure 9, with increasing the lithium content $(\mathrm{S} 1 \rightarrow \mathrm{S} 2 \rightarrow \mathrm{S} 3)$, Stages I and II become narrower, indicating that pitting corrosion occurred more quickly. In addition, S3 shows the largest cumulative number of pits $\left(N_{t}\right)$ within Stage III, owing to high lithium content of S3 that contains more pitting sensitive sites. The $N_{\mathrm{t}}$ of $\mathrm{S} 2$ is the smallest, which may be due to the less grain boundaries as a result of coarse grains, leading to fewer pitting sensitive sites, e.g., intermetallic phases. However, it should be noted that fewer pits does not indicate smaller pits or better corrosion resistance. The size of the pits is more critical for the evaluation of corrosion performance, which will be discussed in a later section.

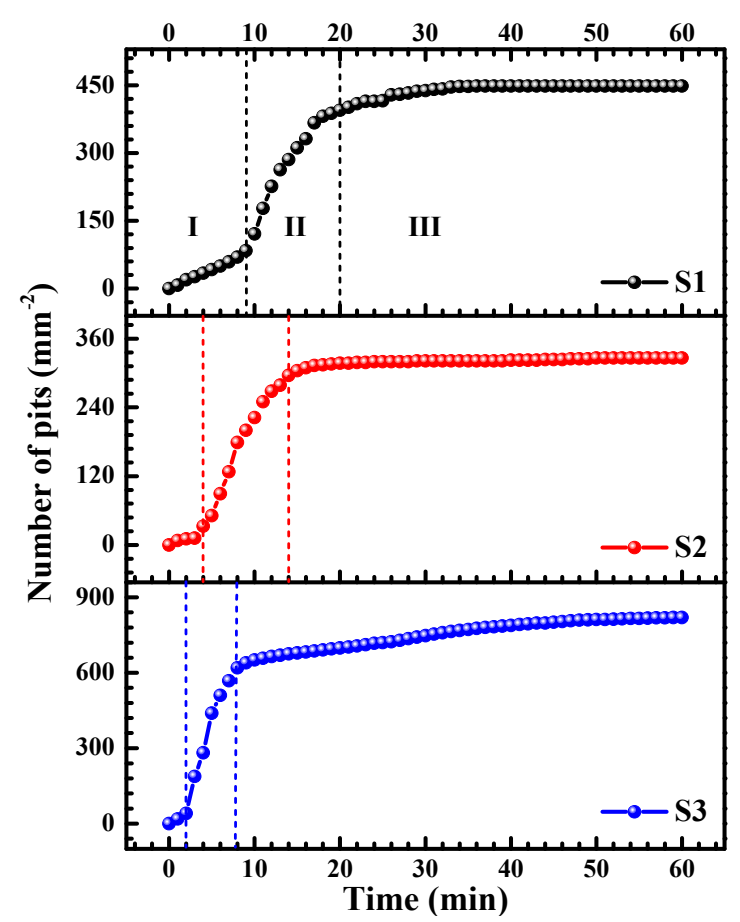

Figure 9. Number of pits vs. immersion time in aerated $0.001 \mathrm{M} \mathrm{NaCl}$ aqueous solution.

\subsubsection{Morphology of Pits}

In order to compare the pitting morphologies of the three alloys, a higher concentration of $\mathrm{Cl}^{-}$ solution $(0.6 \mathrm{M} \mathrm{NaCl}$ solution) was used for the immersion test, and the surface morphologies after immersion for $2 \mathrm{~h}$ are shown in Figure 10. Specimen S3 has a larger number of pits of smaller size than do S1 and S2. The pits on S2 and S3 are linearly concentrated at localized regions. The linear distribution of pits should be due to the elongated grains induced by rolling processing, suggesting a preferential corrosion feature at grain boundaries such as the $\mathrm{T}_{1}$ phase/matrix interfaces for $\mathrm{S} 3$. 


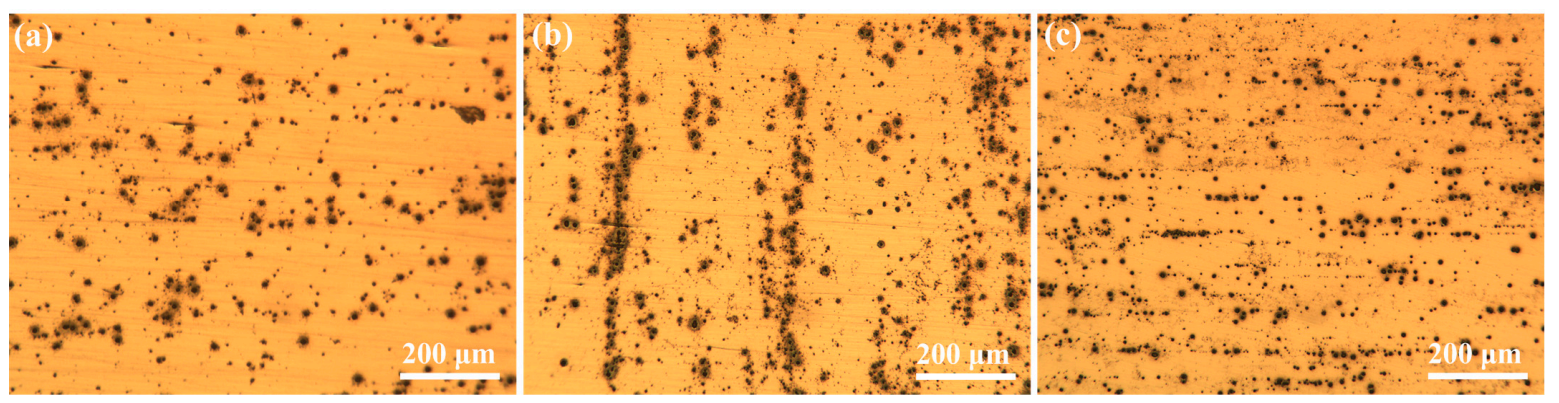

Figure 10. Comparison of the small pits on the aluminum alloys after immersion in aerated $0.6 \mathrm{M} \mathrm{NaCl}$ solution for 2 h: (a) S1, (b) S2, (c) S3.

Another type of pitting damage, classified as severe localized corrosion (SLC) for aluminum alloys [31], was also found on the alloy surfaces after immersion in $0.6 \mathrm{M} \mathrm{NaCl}$ solution for $2 \mathrm{~h}$, as shown in Figure 11. Thus, in Figure 11a, S1 is found to be subjected to intergranular corrosion inside and around the SLC pits, which is evidenced by the grain character inside the SLC pit and shape of the pit edge (see Figure 11b). Detailed examination of the intergranular corrosion features on S1 was performed, and two representative sites are shown in Figure 12. By comparing the morphologies before and after etching, it can be clearly seen that localized corrosion occurred at grain boundaries with an extremely large pit (SLC pit) at the center. According to the shapes of the SLC pits, it is inferred that one or more grains dissolved first at the grain boundaries, i.e., intergranular corrosion occurred to a point that the grain(s) lose bonding with the surrounding matrix and exfoliate from the substrate, leaving an extremely large corrosion pit (50-100 $\mu \mathrm{m}$ opening). The preferred corrosion at grain boundaries for S1 could be due to more intermetallic phases at grain boundaries (see Figures $3 a$ and $4 b$ ) in contrast to the other specimens.
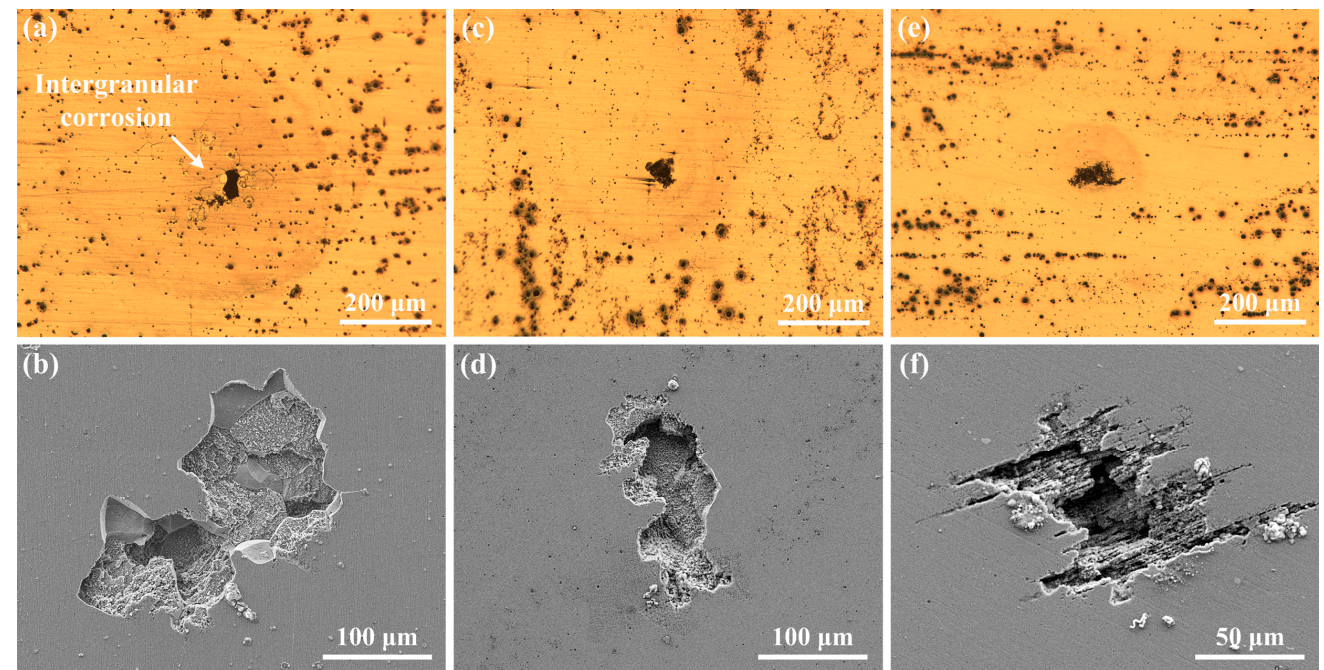

Figure 11. Severe pitting morphologies of the aluminum alloys after immersion in aerated $0.6 \mathrm{M} \mathrm{NaCl}$ solution for 2 h: (a) and (b): S1, (c) and (d): S2, (e) and (f): S3. The uppers are optical images, and the lowers are SEM images. 


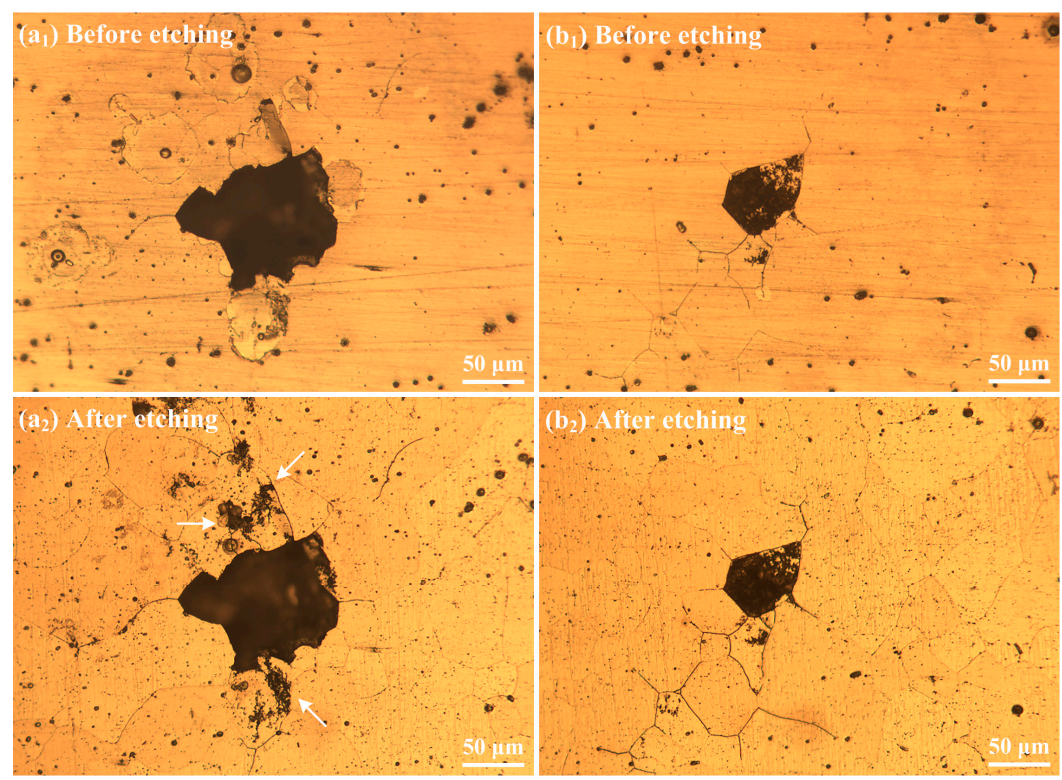

Figure 12. Two representative intergranular corrosion sites on specimen $\mathrm{S} 1$ after immersion in aerated $0.6 \mathrm{M} \mathrm{NaCl}$ solution for $2 \mathrm{~h}$. The specimens were observed without etching ( $\mathbf{a}_{\mathbf{1}}$ and $\mathbf{b}_{\mathbf{1}}$ ) and with etching ( $\mathbf{a}_{2}$ and $\mathbf{b}_{2}$ ).

\subsubsection{Statistical Analysis of Pit Depth}

A 3D optical surface profiler was used to conduct a statistical analysis of the pit depth on the specimens. According to the depth distribution of the pits, they are divided into two groups: depth $<2 \mu \mathrm{m}$ and depth $>2 \mu \mathrm{m}$, as shown in Figures 13 and 14, respectively. Note that the $2 \mu \mathrm{m}$ depth that was used to divide the groups is only for the sake of easier comparison and is of no theoretical significance. Herein, the Percentage $(P)$ is calculated via the equation:

$$
P=\frac{n}{N_{t}} \times 100 \%
$$

where $n$ is the number of a specific depth, $N_{\mathrm{t}}$ is the total number of pits in the present depth range (e.g., in Figure 13, the depth range is $0.5-2 \mu \mathrm{m})$. In Figure 13, the distributions of pit depth for specimens S1 and S2 are similar, and their peaks emerge at $1.3 \mu \mathrm{m}$. However, the largest $P$ for $\mathrm{S} 3$ is at $0.6 \mu \mathrm{m}(\sim 22 \%)$, indicating that $\mathrm{S} 3$ has shallower pits within this range.

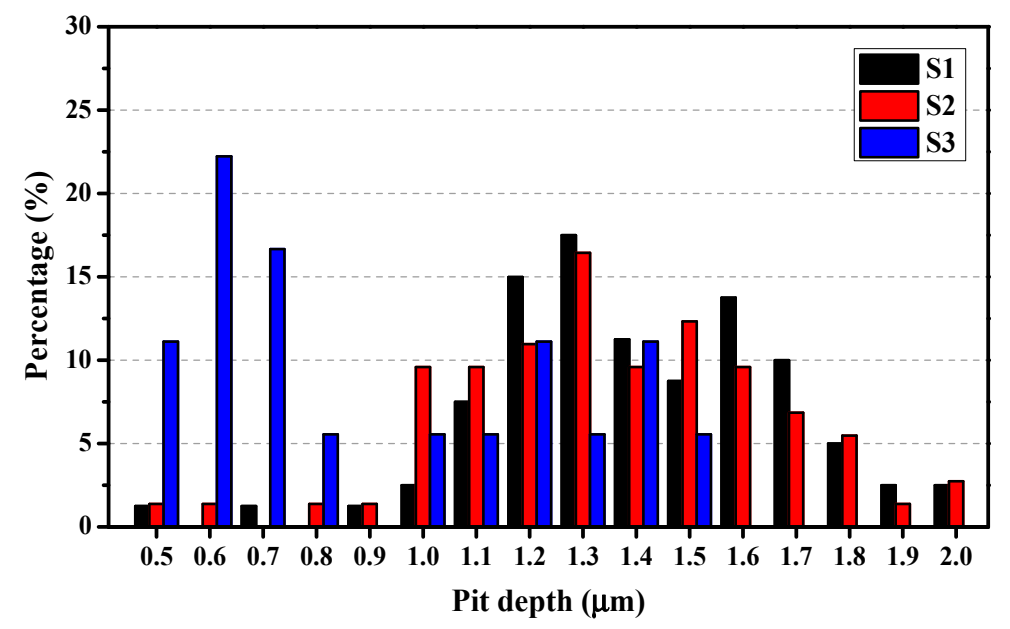

Figure 13. Statistical result for the depth of small pits (depth $<2 \mu \mathrm{m}$ ) after immersion in $0.6 \mathrm{M} \mathrm{NaCl}$ for $2 \mathrm{~h}$. 


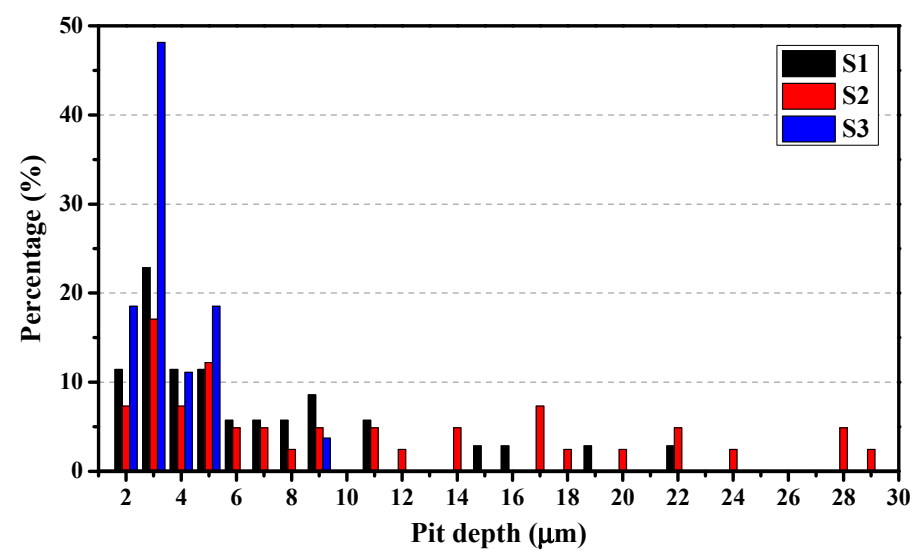

Figure 14. Statistical result for the depth of large pits (depth $>2 \mu \mathrm{m}$ ) after immersion in $0.6 \mathrm{M} \mathrm{NaCl}$ for $2 \mathrm{~h}$.

In Figure 14, the peak values of the three alloys appear at $3 \mu \mathrm{m}$. Nearly $50 \%$ of the pits on $\mathrm{S} 3$ have such depth, and the distribution of the pit depth of S3 is roughly between $2-5 \mu \mathrm{m}$. In comparison, the pit depths of S1 and S2 are widely distributed, particularly for alloy S2, many deep pits $(>20 \mu \mathrm{m})$ can be found. Considering the cumulative numbers of pits in Figure 9 as well as the TEM characterization results in Figure 4, and despite the fact that S3 has much larger number of sensitive sites, the small precipitates in S3 have not caused severe corrosion. The profile images of the deepest SLC pits on the three alloys are shown in Figure 15. The depths of the SLC pits on S1, S2, and S3 are $22.4 \mu \mathrm{m}, 28.6 \mu \mathrm{m}$, and $8.6 \mu \mathrm{m}$, respectively. Clearly, the "mouth" size of the SLC pits may be similar, while the depths of the SLC pits may be very different, which is a testament to the importance of this analysis.

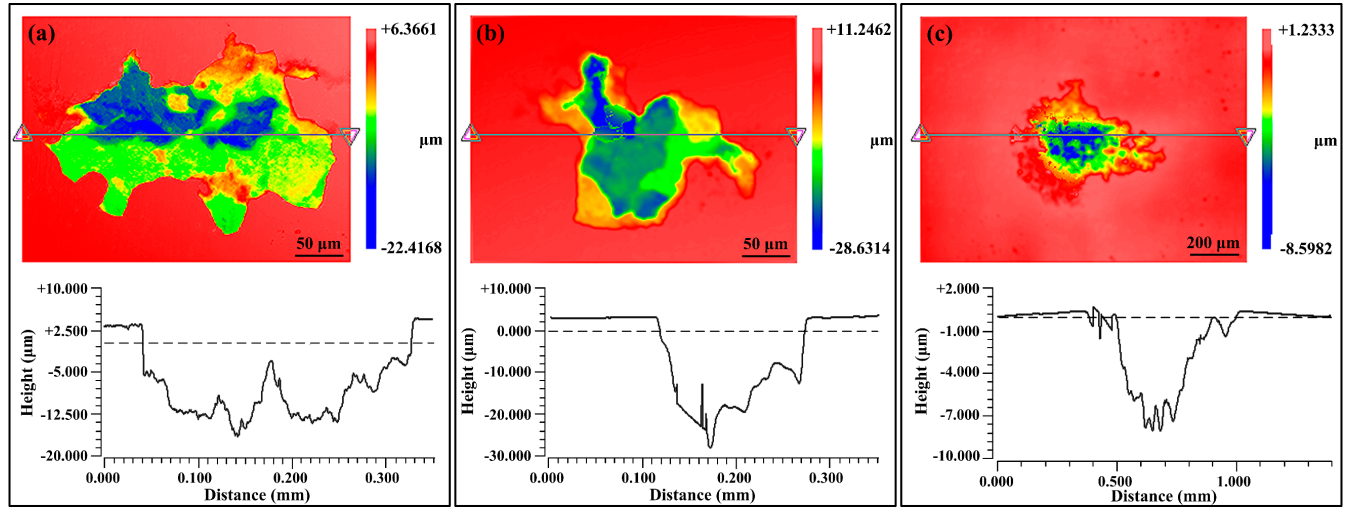

Figure 15. 3D depth profile of the deepest pit on each alloy after immersion in $0.6 \mathrm{M} \mathrm{NaCl}$ solution for 2 h: (a) S1, (b) S2, (c) S3.

\section{Discussions}

\subsection{Effect of Li on Pitting Corrosion}

From the polarization results in Figures 5 and 7, it is indicated that the addition of lithium promotes the pitting resistance of $\mathrm{Al}$ alloy in borate buffer solution. The alloy with higher lithium content shows wider passive range and more stable passive current, suggesting a better passivation behavior. According to Wang et al. [32], lithium participates in the process of film formation and contributes to lower density of oxygen vacancies in the aluminum oxide film. The lowered density of oxygen vacancies decreases the absorption of aggressive anions, the $\mathrm{Cl}^{-}$ion in this case, into oxygen vacancies and, thereby, retards the vacancy condensate at the metal/film interface, leading to enhanced pitting resistance. This mechanism well supports the electrochemical findings of the present work. 
As can be seen from the in-situ observation of the pitting processes of S1, S2, and S3 in $0.001 \mathrm{M}$ $\mathrm{NaCl}$ solution (Figures 8 and 9), the development of pitting corrosion can be divided into an initial, slow nucleation stage (Stage I), a fast development stage (Stage II), and a stabilized growth stage (Stage III). The difference in the development of pitting for the three alloys is the duration of each of the stages. With increasing lithium content, the durations of Stages I and II become shorter. Combining this fact with the SEM and TEM microstructural analyses, the higher rate of pitting initiation and development should be attributed to the higher activity of lithium and the larger numbers of lithium-containing intermetallic phases, such as the abundant $\mathrm{T}_{1}$ precipitates in S3 (see Figure 4e,f) [33-35]. Electrochemical corrosion would take place due to the microcell reaction between the secondary phases and the matrix. The mechanism for the microcell reaction has been well established, based upon the chemical composition of the precipitates, i.e., with/without lithium for Al-Cu-Li alloys, which decides if the precipitate acts as the anode or the cathode within the cell $[16,26,27]$.

In addition, the cumulative number of pits lies in the order of S3 $>\mathrm{S} 1>\mathrm{S} 2$ (see Figure 9), while the sequence of pit depth is $\mathrm{S} 3<\mathrm{S} 1 \approx \mathrm{S} 2$ (Figures 13 and 14 ). This could be due to the greater amount, but smaller size, of the $\mathrm{T}_{1}$ phases in $\mathrm{S} 3$, which act as abundant but small anodes, leading to larger numbers of small pits. In comparison, $\mathrm{S} 1$ and $\mathrm{S} 2$ have fewer, but much larger, precipitates, such as the $\mathrm{S}$ phase for $\mathrm{S} 1$ and $\mathrm{Al}_{20} \mathrm{Cu}_{2} \mathrm{Mn}_{3}$ phase for $\mathrm{S} 2$, respectively, resulting in large pits, but in smaller numbers.

\subsection{From Pitting Corrosion to SLC Pits}

In Figure 11, circular features are observed around the SLC pits. The generation of SLC pits and circular features can be interpreted based upon the in-situ observation results of gas bubbling from the site on $\mathrm{S} 1$ after immersion for $105 \mathrm{~min}$, as shown by the video captured in Figure 16. A similar feature has been described by Bargeron and Givens [36,37]. In Figure 16, as marked by the arrows, a gas bubble was generated in a pit at the center of the circle, then left the alloy surface and finally broke. This process continued at this site during the immersion test, resulting in the continuous consumption of material inside the pit and leading to the formation of a SLC pit. The morphology of the pit, after cleaning the corrosion product, is exhibited in Figure 11a. The gas inside the bubble is presumed to be hydrogen, due to the autocatalytic acidification effect at the tip of SLC pit, which may involve the following reactions for S1 [30]:

$$
\begin{gathered}
\mathrm{H}_{2} \mathrm{O}=\mathrm{H}^{+}+\mathrm{OH}^{-} \\
\mathrm{Al}=\mathrm{Al}^{3+}+3 \mathrm{e}^{-} \\
\mathrm{Al}^{3+}+3 \mathrm{H}_{2} \mathrm{O}^{-}=\mathrm{Al}(\mathrm{OH})_{3}+3 \mathrm{H}^{+}
\end{gathered}
$$

According to Reaction (4), $\mathrm{H}^{+}$is produced by the hydrolysis of $\mathrm{Al}^{3+}$ to form $\mathrm{Al}(\mathrm{OH})_{3}$, thereby lowering the $\mathrm{pH}$ at the pit tip. Reaction (3) provides the electrons that will react with $\mathrm{H}^{+}$to form $\mathrm{H}_{2}$ via the following Reaction (5).

$$
2 \mathrm{H}^{+}+2 \mathrm{e}^{-}=\mathrm{H}_{2} \uparrow
$$

However, it is to be noted that Bargeron and Givens [36,37] observed similar gas evolution, but the gas was identified to be $\mathrm{H}_{2} \mathrm{~S}, \mathrm{NH}_{3}$ or $\mathrm{CH}_{4}$, depending upon the identity of the pit nucleation sites (presumably, sulfide, nitride, and carbide inclusions, respectively).

Reactions (2)-(5) explain the mechanism for the bubbling that continuously occurs at the pitting sites and lead to SLC. The circular feature around the bubbling sites may be attributed to incident spherical shock waves in the liquid upon the collapse of the bubbles [38], pushing away products from the re-precipitation of $\mathrm{Al}^{3+}$ as $\mathrm{Al}(\mathrm{OH})_{3}$ from the solution onto the alloy surface external to the pit via Reaction (4). Interestingly, although the corrosion products had been removed, the circular feature can still be clearly seen in Figure 11, possibly because of the occurrence of under-deposit corrosion. 


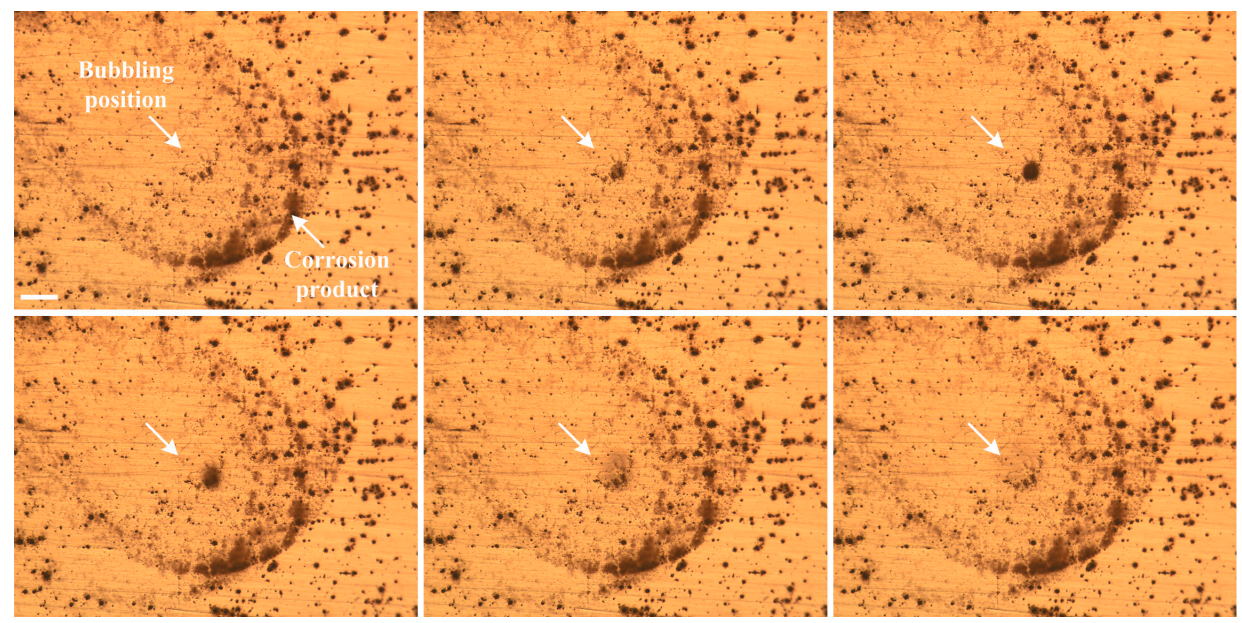

Figure 16. In-situ observation of a gas bubbling site on specimen $\mathrm{S} 1$ in aerated $0.6 \mathrm{M} \mathrm{NaCl}$. Scale bar is $150 \mu \mathrm{m}$.

In addition, it can be seen from Figure 11 that the sizes of the SLC pits are much larger than the surrounding pits, whereas the pits which are adjacent to these SLC pits are smaller in size and fewer in number than those that are further away from the SLC pits. This characteristic is schematically depicted by Figure 17, which is explained by the formation of local microcells: the anodes are the SLC pits, and the adjacent regions are cathodically protected to some significant extent, thereby reducing the nucleation and growth rates of the surrounding pits. Similar morphologies were reported by Donatus et al. [30] for $2198 \mathrm{Al}$ alloy and Ma et al. [31] for $2099 \mathrm{Al}$ alloy. This phenomenon has been previously explained in terms of a "hemisphere of influence (HOI)" centered on the well-established, central pit [39]. The HOI is established by the consumption of the coupling current on from the pit on the external surface by hydrogen evolution and/or oxygen reduction, resulting in a local increase in $\mathrm{pH}$ and hence in the precipitation of $\mathrm{Al}(\mathrm{OH})_{3}$. As the pit ages, it demands more resources from the external surface in terms of the cathodic reaction, resulting in an increase in the throwing power of the current from the pit and hence in the radius of the HOI.

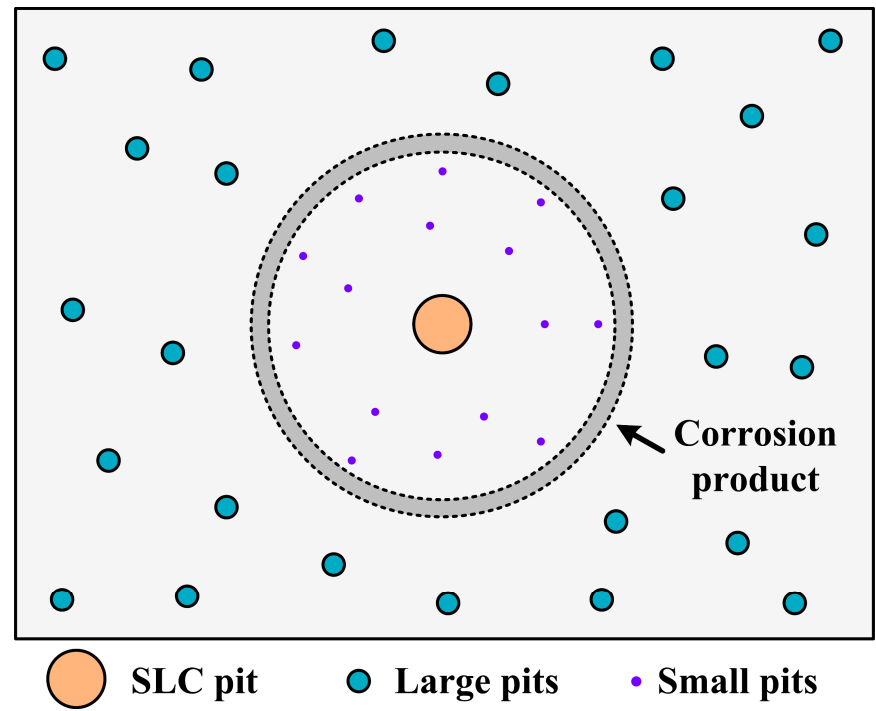

Figure 17. A schematic for the distribution of various sizes of corrosion pits at and near a bubbling site.

To understand the mechanism for the very few SLC pits on specimen S3 which possesses the highest $\mathrm{Li}$ content, the effect of $\mathrm{Li}$ on the acidic level inside the tip of the pits should be considered. 
According to Reactions (2) to (5), the low $\mathrm{pH}$ environment at the tip of the pits is critical for the formation of SLC pits. As Li is very active metal, in the acidic environment at the tip of a pit, the following Reaction (6) may occur along with Reaction (3) [26]:

$$
\mathrm{Li}=\mathrm{Li}^{+}+\mathrm{e}^{-}
$$

Hence, the $\mathrm{H}^{+}$inside the pit will be consumed by the electrons via Reaction (5), and the $\mathrm{pH}$ of the pit is lowered. In other words, lithium could play a critical role in neutralizing the environment and inhibiting the growth of pits into the alloy. Such an effect would be very beneficial for specimen S3, as can be seen from the results of electrochemical measurements (Figure 5 to Figure 7 ) and immersion tests (Figure 8 to Figure 15). However, the advantageous effect of lithium is overwhelmed by the deteriorative effect of the large intermetallic phases that result in the severe corrosion on specimen S2.

\section{Conclusions}

The microstructures and pitting corrosion behavior of AA2029-T8 (S1), AA2060-T8 (S2), and AA2098-T851 (S3), with increasing lithium content, were studied using SEM, TEM, EDS, electrochemical measurements, in-situ observation, and statistical analysis of pit depth observed in immersion test. The principal conclusions are as follows:

(1) The pitting potential of the three alloys lies in the following order: S1 $<$ S2 $<$ S3. With the comparatively highest lithium content, S3 shows the widest passive region and lowest steady-state current density.

(2) The development of the pitting process can be divided in to an initial slow nucleation stage (Stage I), a fast development stage (Stage II), and a stabilized growth stage (Stage III). The accumulative number of pitting sites rises more quickly with increasing lithium content (S1 $\rightarrow \mathrm{S} 2 \rightarrow \mathrm{S} 3$ ), whereas S1 and S2 possess deeper pits than does S3.

(3) Circular characteristics were found near the SLC sites, which should be due to the precipitation of corrosion products on the alloy surfaces external to the pit.

(4) A well-established pit partially protects the surrounding area cathodically, thereby inhibiting the nucleation and growth rates of new pits under the "hemisphere of influence" of the central pit.

Author Contributions: X.L. and D.M. designed the experimental program; X.L., R.D. and W.L. carried out the electrochemical experiments, immersion tests, SEM and TEM characterizations; A.S. and E.G. performed the 3D profiling and statistical analyses of pitting depth; D.M. led the team; X.L. wrote the paper; N.W. and D.M. reviewed and edited the paper.

Funding: This work was supported by the Aviation Science Foundation of China (Grant No. 2017ZF53066), the National Natural Science Foundation of China (Grant No. 51801160), the Natural Science Basic Research Plan in Shaanxi Province of China (Grant No. 2018JQ5091), and the U.S. Air Force Academy under Cooperative Agreement FA7000-14-2-0017.

Acknowledgments: The authors gratefully acknowledge the support by the University of California at Berkeley, Berkeley, CA, USA and Northwestern Polytechnical University, Xi'an, Shaanxi, China.

Conflicts of Interest: The authors declare no conflict of interest.

\section{References}

1. Li, J.F.; Birbilis, N.; Liu, D.Y.; Chen, Y.L.; Zhang, X.H.; Cai, C. Intergranular corrosion of Zn-free and Zn-microalloyed Al-xCu-yLi alloys. Corros. Sci. 2016, 105, 44-57. [CrossRef]

2. Dursun, T.; Soutis, C. Recent developments in advanced aircraft aluminium alloys. Mater. Des. 2014, 56, 862-871. [CrossRef]

3. Prasad, N.E.; Gokhale, A.; Wanhill, R.J.H. Aluminum-Lithium Alloys: Processing, Properties, and Applications; Butterworth-Heinemann: Oxford, UK, 2014.

4. Sinhmar, S.; Dwivedi, D.K. A study on corrosion behavior of friction stir welded and tungsten inert gas welded AA2014 aluminium alloy. Corros. Sci. 2018, 133, 25-35. [CrossRef] 
5. Gui, J.; Devine, T. Influence of Lithium on the Corrosion of Aluminum. Scr. Metall. 1987, 21, $853-857$. [CrossRef]

6. Ma, Y.; Zhou, X.; Liao, Y.; Yi, Y.; Wu, H.; Wang, Z.; Huang, W. Localised corrosion in AA 2099-T83 aluminium-lithium alloy: The role of grain orientation. Corros. Sci. 2016, 107, 41-48. [CrossRef]

7. Ott, N.; Yan, Y.; Ramamurthy, S.; Kairy, S.; Birbilis, N. Auger electron spectroscopy analysis of grain boundary microchemistry in an Al-Cu-Li alloy. Scr. Mater. 2016, 119, 17-20. [CrossRef]

8. Guérin, M.; Alexis, J.; Andrieu, E.; Laffont, L.; Lefebvre, W.; Odemer, G.; Blanc, C. Identification of the metallurgical parameters explaining the corrosion susceptibility in a 2050 aluminium alloy. Corros. Sci. 2016, 102, 291-300. [CrossRef]

9. Guerin, M.; Andrieu, E.; Odemer, G.; Alexis, J.; Blanc, C. Effect of varying conditions of exposure to an aggressive medium on the corrosion behavior of the $2050 \mathrm{Al}-\mathrm{Cu}-\mathrm{Li}$ alloy. Corros. Sci. 2014, 85, 455-470. [CrossRef]

10. Rioja, R.J.; Liu, J. The Evolution of Al-Li Base Products for Aerospace and Space Applications. Metall. Mater. Trans. A 2012, 43, 3325-3337. [CrossRef]

11. Carrick, D.M.; Hogg, S.C.; Wilcox, G.D. Influence of Li Additions on the Microstructure and Corrosion Response of 2XXX Series Aluminium Alloys. Mater. Sci. Forum 2014, 794-796, 193-198. [CrossRef]

12. Buchheit, R.G. The Electrochemistry of $\theta\left(\mathrm{Al}_{2} \mathrm{Cu}\right), \mathrm{S}\left(\mathrm{Al}_{2} \mathrm{CuMg}\right)$ and $\mathrm{T}_{1}\left(\mathrm{Al}_{2} \mathrm{CuLi}\right)$ and Localized Corrosion and Environment Assisted Cracking in High Strength Al Alloys. Mater. Sci. Forum 2000, 331-337, 1641-1646. [CrossRef]

13. Szklarska-Smialowska, Z. Pitting corrosion of aluminum. Corros. Sci. 1999, 41, 1743-1767. [CrossRef]

14. Frankel, G.S. The effects of microstructure and composition on Al alloy corrosion. Corrosion 2015, 71, 1308-1320. [CrossRef]

15. Ma, Y.; Zhou, X.; Huang, W.; Liao, Y.; Chen, X.; Zhang, X.; Thompson, G.E. Crystallographic defects induced localised corrosion in AA2099-T8 aluminium alloy. Corros. Eng. Sci. Technol. 2014, 50, 420-424. [CrossRef]

16. Li, J.F.; Li, C.X.; Peng, Z.W.; Chen, W.J.; Zheng, Z.Q. Corrosion mechanism associated with T1 and T2 precipitates of Al-Cu-Li alloys in $\mathrm{NaCl}$ solution. J. Alloys Compd. 2008, 460, 688-693. [CrossRef]

17. Wang, J.; Zhang, B.; Wu, B.; Ma, X.L. Size-dependent role of S phase in pitting initiation of 2024Al alloy. Corros. Sci. 2016, 105, 183-189. [CrossRef]

18. Wei, W.; González, S.; Hashimoto, T.; Prasath Babu, R.; Thompson, G.E.; Zhou, X. Effect of low temperature sensitization on the susceptibility to intergranular corrosion in AA5083 aluminum alloy. Mater. Corros. 2016, 67, 331-339. [CrossRef]

19. Niskanen, P.; Sanders, T.; Rinker, J.; Marek, M. Corrosion of aluminum alloys containing lithium. Corros. Sci. 1982, 22, 283-304. [CrossRef]

20. Zweiacker, K.W.; Liu, C.; Gordillo, M.A.; McKeown, J.T.; Campbell, G.H.; Wiezorek, J.M.K. Composition and automated crystal orientation mapping of rapid solidification products in hypoeutectic $\mathrm{Al}-4$ at.\%Cu alloys. Acta Mater. 2018, 145, 71-83. [CrossRef]

21. Deschamps, A.; Garcia, M.; Chevy, J.; Davo, B.; De Geuser, F. Influence of Mg and Li content on the microstructure evolution of Al-Cu-Li alloys during long-term ageing. Acta Mater. 2017, 122, 32-46. [CrossRef]

22. Wang, S.C.; Starink, M.J. Precipitates and intermetallic phases in precipitation hardening Al-Cu-Mg-(Li) based alloys. Int. Mater. Rev. 2005, 50, 193-215. [CrossRef]

23. Huang, B.P.; Zheng, Z.Q. Effects of Li content on precipitation in Al-Cu-(Li)-Mg-Ag-Zr alloys. Scr. Mater. 1998, 38, 357-362. [CrossRef]

24. Kumai, C.; Kusinski, J.; Thomas, G.; Devine, T. Influence of aging at $200 \mathrm{C}$ on the corrosion resistance of Al-Li and Al-Li-Cu alloys. Corrosion 1989, 45, 294-302. [CrossRef]

25. Duan, S.Y.; Wu, C.L.; Gao, Z.; Cha, L.M.; Fan, T.W.; Chen, J.H. Interfacial structure evolution of the growing composite precipitates in Al-Cu-Li alloys. Acta Mater. 2017, 129, 352-360. [CrossRef]

26. Li, J.F.; Zheng, Z.Q.; Jiang, N.; Li, S.C. Study on localized corrosion mechanism of 2195 Al-Li alloy in $4.0 \%$ $\mathrm{NaCl}$ solution ( $\mathrm{pH}$ 6.5) using a three-electrode coupling system. Mater. Corros. 2005, 56, 192-196. [CrossRef]

27. Li, J.F.; Zheng, Z.Q.; Li, S.C.; Chen, W.J.; Ren, W.D.; Zhao, X.S. Simulation study on function mechanism of some precipitates in localized corrosion of Al alloys. Corros. Sci. 2007, 49, 2436-2449. [CrossRef]

28. Yoshimura, R.; Konno, T.J.; Abe, E.; Hiraga, K. Transmission electron microscopy study of the evolution of precipitates in aged Al-Li-Cu alloys: The $\theta^{\prime}$ and $\mathrm{T}_{1}$ phases. Acta Mater. 2003, 51, 4251-4266. [CrossRef] 
29. Hashimoto, T.; Zhang, X.; Zhou, X.; Skeldon, P.; Haigh, S.J.; Thompson, G.E. Investigation of dealloying of $S$ phase $\left(\mathrm{Al}_{2} \mathrm{CuMg}\right)$ in $\mathrm{AA} 2024-\mathrm{T} 3$ aluminium alloy using high resolution 2D and 3D electron imaging. Corros. Sci. 2016, 103, 157-164. [CrossRef]

30. Donatus, U.; Terada, M.; Ospina, C.R.; Queiroz, F.M.; Fatima Santos Bugarin, A.; Costa, I. On the AA2198-T851 alloy microstructure and its correlation with localized corrosion behaviour. Corros. Sci. 2018, 131, 300-309. [CrossRef]

31. Ma, Y.; Zhou, X.; Huang, W.; Thompson, G.E.; Zhang, X.; Luo, C.; Sun, Z. Localized corrosion in AA2099-T83 aluminum-lithium alloy: The role of intermetallic particles. Mater. Chem. Phys. 2015, 161, 201-210. [CrossRef]

32. Wang, H.N.; Liu, C.Z.; Lu, L.; Li, R.S.; Lin, D. Effect of Li content on electrochemical corrosion behavior for Al-Li alloy in acidic NaCl solution. Rare Met. Mater. Eng. 2018, 47, 1445-1450.

33. Zhang, X.; Zhou, X.; Hashimoto, T.; Liu, B.; Luo, C.; Sun, Z.; Tang, Z.; Lu, F.; Ma, Y. Corrosion behaviour of 2A97-T6 Al-Cu-Li alloy: The influence of non-uniform precipitation. Corros. Sci. 2018, 132, 1-8. [CrossRef]

34. Huang, J.-L.; Li, J.-F.; Liu, D.-Y.; Zhang, R.-F.; Chen, Y.-L.; Zhang, X.-H.; Ma, P.-C.; Gupta, R.K.; Birbilis, N. Correlation of intergranular corrosion behaviour with microstructure in Al-Cu-Li alloy. Corros. Sci. 2018, 139, 215-226. [CrossRef]

35. Zhang, X.; Zhou, X.; Hashimoto, T.; Lindsay, J.; Ciuca, O.; Luo, C.; Sun, Z.; Zhang, X.; Tang, Z. The influence of grain structure on the corrosion behaviour of 2A97-T3 Al-Cu-Li alloy. Corros. Sci. 2017, 116, 14-21. [CrossRef]

36. Bargeron, C.B.; Givens, R.B. Precursive blistering in the localized corrosion of aluminum. Corrosion 1980, 36, 618-625. [CrossRef]

37. Bargeron, C.B.; Givens, R.B. Blister formation and pitting corrosion in aluminum. J. Electrochem. Soc. 1978, 125, C119.

38. Buravova, S.N.; Gordopolov, Y.A. Cavitation erosion as a kind of dynamic damage. Int. J. Fract. 2011, 170, 83-93. [CrossRef]

39. Macdonald, D.D.; Engelhardt, G.R. Predictive Modeling of Corrosion; Elsevier Science Bv: Amsterdam, The Netherlands, 2010; pp. 1630-1679.

(C) 2019 by the authors. Licensee MDPI, Basel, Switzerland. This article is an open access article distributed under the terms and conditions of the Creative Commons Attribution (CC BY) license (http://creativecommons.org/licenses/by/4.0/). 